Methods: The study consisted of 35 RA cases in MCSA and 104 MCSA participants without RA matched 1:3 for age, sex, education, cognitive status ( $\geq 50$ years old) at baseline and the availability of at least one magnetic resonance imaging (MRI). The primary outcome measures were well established dementia-related neuroimaging biomarkers, including global beta-amyloid $(A \beta)$ using PiB-positron-emission tomography (PET; $n=47$ ); neurodegeneration (hypometabolism via FDG-PET $(n=45)$, hippocampal volume $(n=139)$, and cortical thickness via structural MRI $[n=138]$, and cerebrovascular pathology via FLAIRMRI (white matter hyperintensity [WMH; $n=49$ ] burden, subcortical, and cortical infarctions $(n=55)$ ). Elevated ${ }^{11} \mathrm{C}$-PiB-PET was defined as standardized uptake value ratio $\geq 1.48$ in an Alzheimer's disease (AD)-related region of interest and reduced $A D$ signature cortical thickness as $\leq 2.68 \mathrm{~mm}$ (neurodegeneration; $\mathrm{N}+$ ). Kruskal-Wallis rank sum and Pearson's chi-squared tests were used to compare the neuroimaging measures between participants with and without RA.

Results: Participants with vs. without-RA did not differ in age, sex, years of education, major comorbidities, $A \beta$ burden, hippocampal volume, and neurodegeneration measures (Table 1). Although the sample size was small, we observed that RA participants (vs. without-RA) had greater mean WMH volume (relative to the total intracranial volume (TIV) (mean (SD) \%: $1.12(0.57) \%$ vs $0.76(0.69)$ $\%$ of TIV, $p=0.011$ ), were more likely to have cortical infarctions ( $4 \mathrm{vs.1} ; p=0.013$ ) and had a higher mean number of cortical infarctions (mean (SD): $0.24(0.44)$ vs. 0.05 (0.32), $p=0.017)$.

Conclusion: Our preliminary data suggest significant differences in cerebrovascular biomarker measures by RA status. Further studies would add valuable information to our understanding and insight into the development of interventions for the prevention of cerebrovascular pathology in RA patients.

REFERENCES:

[1] Dregan, A., P. Chowienczyk and M. C. Gulliford (2015). "Are Inflammation and Related Therapy Associated with All-Cause Dementia in a Primary Care Population?" J Alzheimers Dis 46(4): 1039-1047.

Table 1. Participants' baseline characteristics.

\begin{tabular}{lcccc}
\hline & With RA & Without RA & Total & p value* \\
\hline Age, mean (SD) & $76.3(7.9)$ & $75.9(7.9)$ & 139 & 0.82 \\
Male & $13(37 \%)$ & $37(36 \%)$ & 139 & 0.87 \\
Education (years), mean (SD) & $14.5(2.5)$ & $14.3(2.4)$ & 139 & 0.75 \\
Apolipoprotein E 4 carrier & $6(17 \%)$ & $28(27 \%)$ & 139 & 0.24 \\
Cognitively unimpaired & $27(77 \%)$ & $83(80 \%)$ & 110 & 0.94 \\
Mild cognitive impairment & $7(20 \%)$ & $18(17 \%)$ & 25 & \\
Dementia & $1(3 \%)$ & $3(3 \%)$ & 4 & \\
Reduced AD signature cortical thickness & $20(57 \%)$ & $60(58 \%)$ & 138 & 0.91 \\
Elevated $\beta$-amyloid & $4(33 \%)$ & $11(31 \%)$ & 47 & 0.90 \\
FDG PET SUVR & $1.52(0.16)$ & $1.59(0.18)$ & 45 & 0.46 \\
White matter hyperintensity volume \% of TIV & $1.12(0.57)$ & $0.76(0.69)$ & 49 & 0.011 \\
With cortical infarctions & $4(24 \%)$ & $1(3 \%)$ & 55 & 0.013
\end{tabular}

$\mathrm{N}(\%)$ unless otherwise stated; * Kruskal-Wallis rank sum or Pearson's Chi-squared test.SD=standard deviation; $A D=$ Alzheimer's disease; $S U V R=$ standardized uptake value ratio; TIV= Total intracranial volume.

Acknowledgements: The study was supported by the NIH AG068192. The Mayo Clinic Study of Aging was supported by the NIH (U01 AG006786, P50 AG016574, R01AG057708, R01 AG011378, R01 AG021927, R01 AG041851, R01 NS097495), the Alexander Family Alzheimer's Disease Research Professorship of the Mayo Clinic, Mayo Foundation for Medical Education and Research, the Liston Award, the Schuler Foundation and was made possible by the Rochester Epidemiology Project (R01 AG034676).

Disclosure of Interests: Maria Vassilaki Shareholder of: M. Vassilaki has equity ownership in Abbott Laboratories, Johnson and Johnson, Medronic and Amgen. Grant/research support from: M. Vassilaki has received research funding from Roche and Biogen in the past., Cynthia S. Crowson: None declared, John M Davis III Grant/research support from: JM. Davis III receives research funding from Pfizer., Stephanie Duong: None declared, David Jones: None declared, Michelle Mielke Consultant of: M. Mielke has consulted for Biogen and Brain Protection Company, Prashanthi Vemuri: None declared, Elena Myasoedova: None declared

DOI: 10.1136/annrheumdis-2021-eular.1137

\section{POS0312 HOW DOES THE PRESENCE OF DEPRESSION IMPACT ON DISEASE ACTIVITY SCORES IN PATIENTS WITH RHEUMATOID ARTHRITIS?}

C. A. Isnardi ${ }^{1}$, E. E. Schneeberger ${ }^{1}$, D. Capelusnik ${ }^{1}$, M. Bazzarelli ${ }^{2}$, L. Barloco ${ }^{3}$, E. S. Blanco ${ }^{4}$, A. Benitez ${ }^{4}$, F. Benavidez ${ }^{4}$, S. Scarafia ${ }^{5}$, M. A. Lazaro ${ }^{5}$, R. Perez Alamino $^{6}$, F. Colombres ${ }^{6}$, M. P. Kohan ${ }^{7}$, J. Sosa ${ }^{7}$, L. Gonzalez Lucero ${ }^{8}$, A. L. Barbaglia ${ }^{8}$, H. Maldonado Ficco ${ }^{9}$, G. Citera ${ }^{1} .{ }^{1}$ Psychophysical Rehabilitation Institute, Rheumatology, DQG, Argentina; ${ }^{2}$ Hospital Provincial Petrona V. de Cordero, Rheumatology, San Fernando, Argentina; ${ }^{3}$ Hospital Provincial Petrona V. de Cordero, Terapia ocupacional, San Fernando, Argentina; ${ }^{4}$ General Hospital
Dr. Cosme Argerich Treble, Rheumatology, AHD, Argentina; ${ }^{5}$ IARI-Instituto de Asistencia Reumatológica Integral, Rheumatology, San Fernando, Argentina; ${ }^{6}$ Hospital de Clínicas Nicolás Avellaneda, Rheumatology, San Miguel de Tucumán, Argentina; ${ }^{7}$ Dr. Enrique Tornú Hospital, Rheumatology, Ciudad de Buenos Aires, Argentina; ${ }^{8}$ Hospital Ángel C. Padilla, Rheumatology, San Miguel de Tucumán, Argentina; ${ }^{9}$ Nuevo Hospital Río Cuarto "San Antonio de Padua", Rheumatology, Río Cuarto, Argentina

Background: Depression is present in up to half of patients with Rheumatoid Arthritis (RA). The association between this mood disorder and disease activity scores, including DAS28, SDAI and CDAI, has previously been described by various authors. Objectives: The aim of our study was assessed the effect of depression on the components of different disease activity scores.

Methods: We performed a cross-sectional study of consecutive adults with RA, according to ACR/EULAR 2010 criteria. Sociodemographic data, comorbidities and current treatment were recorded. Disease activity was evaluated using DAS28-ESR, DAS28-CRP, SDAI and CDAI. Depression was assessed using PHQ-9 questionnaire. The PHQ-9 values were categorized in 4 groups as follows: 5 to 9,10 to 14,15 to 19,20 or greater, represents mild, moderate, moderate/severe, and severe depression, respectively. A cutoff value of 10 or greater was set to define major depression. Statistical analysis: Student's T, ANOVA and $\mathrm{Chi}^{2}$ tests. Multiple logistic regression.

Results: Two hundred fifty eight patients were included, with a median $(m)$ disease duration of 9 years (IQR 3.6-16.7). The $m$ PHQ-9 score was 6 (IQR 2-12.3) and the prevalence of major depression was $33.7 \%$. Patients with major depression had more tender and swollen joint count (TJC and SJC) (mean $4.9 \pm 4.3 \mathrm{vs}$ $2.3 \pm 3.7, p<0.0001$ and $2.9 \pm 3.3$ vs $1.7 \pm 3.4, p=0.009$ ), more pain $(V A S[\mathrm{~cm}]$ mean $5.6 \pm 2.7$ vs $3.3 \pm 2.6, p<0.0001$ ), higher patient and physician global assessment (PGA and PhGA) (VAS [cm] mean $5.4 \pm 2.9$ vs $3.1 \pm 2.5, p<0.0001$ and $4.4 \pm 2.7$ vs $2.4 \pm 2.4, p<0.0001$ ) and CRP (mean $1.7 \pm 3.3$ vs $0.7 \pm 1.1 \mathrm{mg} / \mathrm{dl}, \mathrm{p}=0.01$ ). ESR values were higher in the group with major depression, but the difference did not reach significance. Disease activity was higher in the depression group by all scores: DAS28-ESR (mean $4.3 \pm 1.4$ vs $3.3 \pm 1.3, p<0.0001$ ), DAS28-CRP (mean $3.9 \pm 1.4$ vs $2.8 \pm 1.7, p<0.0001$ ), SDAl (mean $19.2 \pm 12.7$ vs $10.3 \pm 10.1, p<0.0001$ ) and CDAl (mean $17.6 \pm 10.9$ vs $9.6 \pm 9.9, p<0.0001)$. While $41(15.9 \%)$ patients had high disease activity according to DAS28-ESR, only 34 (13.2\%) had SDAI>26. In the multivariate analysis, evaluating the association of major depression with the different components of DAS28-ESR, DAS28-CRP, SDAI and CDAI, we observed that the presence of this mood disorder remained significantly associated with higher PGA in all the scores. In addition, a significant association was seen with higher TJC in both DAS28 scores.

Conclusion: Patients with major depression had higher disease activity. It's presence has a significantly association with the subjective items of the disease activity scores, particularly PGA. CRP value was the only objective component associated with depression

Disclosure of Interests: Carolina Ayelen Isnardi Speakers bureau: Bristol Myers Squibb, Janssen, Grant/research support from: Pfizer, Emilce Edith Schneeberger Speakers bureau:Abbvie, Amgen, Bristol Myers Squibb, Janssen, Eli Lilly, Boehringer Ingelheim, Pfizer, Genzyme, Grant/research support from: Pfizer, Dafne Capelusnik Speakers bureau: Bristol Myers Squibb, Grant/research support from: Pfizer, Marcela Bazzarelli: None declared, Laura Barloco: None declared, Eliana Soledad Blanco: None declared, Alejandro Benitez Speakers bureau: Abbvie, Novartis, Amgen, Federico Benavidez: None declared, SANTIAGO SCARAFIA: None declared, María Alicia Lazaro Speakers bureau: Abbvie, Rodolfo Perez Alamino Speakers bureau: Pfizer, Abbvie, Amgen, Bristol-Myers-Squibb, Lilly, Janssen, Novartis, Federico Colombres: None declared, María Paula Kohan: None declared, Julia Sosa: None declared, Luciana Gonzalez Lucero: None declared, Ana Lucía Barbaglia: None declared, Hernan Maldonado Ficco Speakers bureau: Pfizer, Abbvie, Jansen, Novartis, Bago, Bristol, Eli Lilly., Consultant of: Pfizer, Abbvie, Novartis, Jansen, Bago, Eli Lilly., Gustavo Citera Speakers bureau: Abbvie, Bristol-Myers-Squibb, Lilly, Jansen, Gema, Pfizer, Roche, Grant/research support from: Pfizer DOI: 10.1136/annrheumdis-2021-eular.1374

\section{POS0313 INCIDENCE AND PREVALENCE OF POLYAUTOIMMUNITY IN SEROPOSITIVE COMPARED WITH SERONEGATIVE PATIENTS WITH RHEUMATOID ARTHRITIS: A NATIONWIDE COHORT STUDY}

A. Hagelskjær ${ }^{1}$, R. Cordtz ${ }^{1}$, S. Bliddal ${ }^{2}$, A. S. Mortensen ${ }^{1}$, S. Kristensen ${ }^{1,3}$ C. H. Nielsen ${ }^{4}$, U. Feldt-Rasmussen ${ }^{2,5}$, C. Torp-Pedersen ${ }^{6}$, L. Dreyer ${ }^{1,3,7}$. ${ }^{1}$ Aalborg University Hospital, Department of Rheumatology, Aalborg, Denmark; ${ }^{2}$ Copenhagen University Hospital, Rigshospitalet, Department of Medical Endocrinology and Metabolism, København, Denmark; ${ }^{3}$ Aalborg University, Department of Clinical Medicine, Aalborg, Denmark; ${ }^{4}$ Copenhagen University Hospital, Rigshospitalet, Institute of Inflammation Research, København, Denmark; ${ }^{5}$ University of Copenhagen, Department of Clinical Medicine, Copenhagen, Denmark; ${ }^{6}$ North Zealand Hospital - Hillerød, Department of Cardiology, Hillerød, Denmark; ${ }^{7}$ DANBIO, Denmark, Nationwide, Denmark 